\title{
Anatole Louis Garraux e o comércio de livros franceses em São Paulo (1860-1890)1
}

Anatole Louis Garraux and the trade of French books in São Paulo (1860-1890)

Marisa Midori Deaecto*

\section{RESUMO}

O presente artigo busca recuperar o papel de Anatole Louis Garraux na promoção do comércio de livros franceses em São Paulo. Negociante natural de Paris, instalou-se na capital paulistana em 1860 , vindo a se tornar o maior livreiro da cidade nas últimas décadas do século. Entre o processo de instalação da Casa Garraux e sua consagração no meio intelectual citadino, descobrimos que foram variados os seus empreendimentos e suas relações com o comércio franco-brasileiro. Todas, porém, situam-se no período de expansão do comércio de bens de consumo importados. Nesse sentido, o problema da circulação do livro será abordado na perspectiva de expansão do capitalismo editorial francês e das condições de consumo de livros existentes na capital.

Palavras-chave: São Paulo; livros; Casa Garraux.

\section{ABSTRACT}

This article approaches some aspects of the bookseller Anatole Louis Garraux and the environment of the French publishing market in São Paulo. A French businessmen that came to this city in 1860 , he became its biggest bookseller in the end of 19th century. Between the foundation of Casa Garraux and his recognition by city's intellectuals, we have found out his business had been become diversified in French-Brazilian trade. All of them, however, are located in time of international trade expansion of consumer goods. On this way, book will be approached by the point of view of Publishing Capitalism expansion and the consumption potential observed in the city.

Keywords: São Paulo; books; Casa Garraux.

\footnotetext{
${ }^{\star}$ Doutora em História - FFLCH-USP - Rua Praia Grande, 45 - Condominio Capital Ville, Lote F-45, Jordanésia. 07750-000 Cajamar - SP - Brasil. marisamidori@yahoo.com.
} 
Como escreve Angel Rama, no século XIX as elites letradas latino-americanas viveram sob o signo da "palingenesia do Iluminismo". Ao traduzir esse fenômeno para o Brasil, podemos afirmar, à luz de um homem culto da época, que eram francesas as aspirações dos jovens doutores do Oitocentos, assim como foram notadamente afrancesadas as referências literárias do século. Nas palavras de Joaquim Nabuco:

No Rio de Janeiro ou em São Paulo, quem se alimente de política, quando a sensação de um grande acontecimento se apossa dele, não encontra nada em redor de si que a corrija ou lhe sirva de contrapeso; felizmente, os acontecimentos grandes são raros. Para um jovem brasileiro, porém, que chega a Paris, é quase impossível imaginar acontecimento que possa torná-lo indiferente ao maravilhoso que o surpreende a cada passo, ou sensação política que não fosse amortecida, dominada logo, pela sensação de arte. ${ }^{2}$

A tomada de consciência desse traço de nossa cultura letrada guiou as investigações literárias e historiográficas para um campo de pesquisa atualmente muito difundido, que se convencionou chamar de história do livro e das práticas de leitura. Na realidade, não são privilégio nosso as investidas sobre o universo livresco dos séculos XVIII e XIX com vistas à recepção da literatura francesa, mas de todos os países que viveram sob o signo e as paixões da Revolução de 1789 e dos ideólogos que consolidaram seus princípios.

No que tange à produção historiográfica brasileira, faz-se imperiosa a lembrança de Eduardo Frieiro e de seu vigoroso ensaio O diabo na livraria do cônego. Sobre o cônego Luís Vieira da Silva, escreve o autor:

Era um afrancesado? Pode-se admiti-lo. As idéias francesas contagiavam alguns brasileiros seletos daquele tempo. Constituíam, é claro, uma reduzida minoria, mas pode-se admitir, como se tem admitido, que tais idéias influíram no pensamento autonomista dos conjurados mineiros, junto com razões mais fortes, de ordem econômica e afetiva, como o grande receio da derrama, o sentimento nativista e a hostilidade ao português. ${ }^{3}$

Diante dessas premissas, tornou-se necessário compreender por quais meios os livros chegaram à colônia, quais os mecanismos utilizados para ludibriar a censura e, também, de que forma as leituras se convertiam, em determinadas conjunturas e espaços, em projetos de natureza sediciosa. Referimo-nos aos estudos sobre as matrizes culturais ou ideológicas da Inconfidência 
Mineira e da Conjuração Baiana, sobre os sediciosos fluminenses e pernambucanos e assim por diante. Afinal, os momentos de crise são raros na História e nem sempre o historiador se convence de que fatos aparentemente importantes provocaram rupturas na ordem vigente. A Revolução de 1789 continuava a ser um modelo para as gerações vindouras, pelo menos no conteúdo das leituras e no grau de interesse que a França e seus intelectuais passaram a despertar em todo o mundo. Ou melhor, em uma fração significativa do globo sensível às referências francófonas.

Destarte, os estudiosos do livro passaram a se interrogar se, nesse mesmo sistema em que uma literatura de conteúdo político e de raízes francesas circulava em abundância — pois sabemos que mesmo os autores ingleses muitas vezes chegavam até nós via França ${ }^{4}$ - não haveria espaço para a difusão de outra sorte de livros. Questiona-se a possibilidade de difundir uma literatura beletrista, ou mesmo de caráter religioso, que viesse satisfazer os gostos das pessoas comuns, permitindo a organização de um circuito paralelo e expressivo de práticas de leituras. E, naturalmente, de espaços que pudessem acolher, além de leitores tradicionais, uma camada de letrados emergente no meio urbano. Seriam, enfim, estudos comprometidos com os mecanismos de produção e com os circuitos de circulação e consumo da literatura francesa durante o século XIX.

A primeira obra de síntese sobre as condições de produção e de comércio editorial foi elaborada por Laurence Hallewell, em O livro no Brasil, cuja primeira edição em português data de $1985 .{ }^{5}$ A publicação é resultado de sua tese de doutoramento, defendida na Universidade de Essex, em 1975, sob o título Uma história da indústria editorial brasileira, com referência particular à publicação de obras literárias. Segundo o autor, "o objetivo básico desse trabalho [era o de] demonstrar como o desenvolvimento da literatura brasileira foi determinado pelas circunstâncias econômicas, práticas comerciais e condições técnicas da indústria nacional" (Hallewell, 1985, p.XXIV).

Poderíamos protestar certo grau de determinismo em suas hipóteses, sobretudo quando o autor vincula de modo direto e exclusivo o desenvolvimento da atividade literária às condições materiais de produção e de consumo. A esse esquema, seria necessário acrescentar os fatores específicos de criação e de recepção das manifestações literárias de uma época. No entanto, se compreendermos o que o autor classifica como "desenvolvimento da literatura brasileira” não exatamente do ponto de vista de suas manifestações estéticas, mas exclusivamente a partir de suas condições infra-estruturais de reprodução, tem sentido a questão desse estrangeiro que encontrou no Brasil um vo- 
lume bastante significativo de livros e, como ele mesmo o atesta, de livros de boa qualidade em seu planejamento gráfico e em sua apresentação física.

Nos capítulos dedicados a São Paulo o autor observa dois grandes momentos.

Comecemos pelo último, pois este foge ao escopo do presente trabalho. O segundo momento, sobre o qual o autor afere o significado de uma verdadeira revolução industrial no mundo dos livros, de textos nacionais e de traduções, foi inaugurado por Monteiro Lobato, após a Primeira Guerra Mundial. A atenção do autor para sua denodada trajetória não se resume ao longo capítulo que lhe consagra, mas à própria dedicatória expressa no livro, que traz no verso da folha de rosto uma reprodução fotográfica do "furacão da Botocúndia” e, em seguida, uma dedicatória ao pai, Laurence Joseph Hallewell, a quem compara com Monteiro Lobato.

Já o primeiro momento, que nos interessa de modo direto, caracterizase pela emergência do comércio livreiro na capital, em grande medida motivado pela presença da Academia de Direito e por uma série de fatores que acenavam para o desenvolvimento econômico e social do burgo de estudantes, a partir das décadas de 1860 e 1870. A expansão da cafeicultura, a urbanização, a instalação de setores econômicos modernos, como bancos, comércio de importação e exportação, empresas de serviços públicos, transportes marítimos etc., a emergência de uma aristocracia cada vez mais alinhada aos padrões de vida urbanos e o espessamento das camadas médias mudaram a feição da cidade. Porém, vale frisar, nada disso teria efeito sobre o mercado de bens culturais se as atividades do espírito não tivessem sido incorporadas e criado raízes no seio da cidade e de suas elites.

Porém, é preciso avaliar o comportamento da economia nacional do livro e seus pontos de contato com o mercado externo. Ora, nesse momento a produção editorial européia vive sob os efeitos da revolução nos meios de produção, o que resultou na massificação da palavra impressa. Nos países periféricos, temos uma situação de concorrência desigual com o produto europeu, que se expressa no aumento da importação de livros estrangeiros. Em especial, das letras francesas.

Neste ponto, parece necessária uma última ressalva. Os circuitos do livro se apóiam sobre a tradição, mesmo quando eles se organizam através da ação de agentes inovadores no meio cultural. Isso quer dizer que o "circuito da inovação" não implica necessariamente uma ruptura com os padrões existentes. Destarte, devemos considerar que a ampla difusão do livro francês, fato comprovado no estudo dos catálogos da Casa Garraux, conforme veremos mais 
adiante, é fruto de uma longa tradição que vinha sendo fundada desde o final do Setecentos, por uma elite intelectual formada nas instituições européias, e que teve nas Academias de Direito o impulso necessário para seu desenvolvimento. Resta, pois, averiguar os mecanismos econômicos e culturais ${ }^{7}$ que moldaram as sensibilidades dos leitores da época e seus pontos de contato com a economia do livro.

A trajetória profissional de Anatole Louis Garraux chama a atenção por duas razões: pelo caráter pioneiro de implantação de uma rede de negócios estabelecida entre as empresas editoriais francesas e o mercado paulista, pois anteriormente a importação de livros dependia do comércio fluminense; e pela recepção de livros franceses, confirmando a preeminência da cultura gaulesa no meio letrado local. É sobre estes dois pontos que devemos nos pautar nas linhas que se seguem.

NegÓCIOS E ÓCIOS OU A BUSCA DE UM PERFIL BIOGRÁFICO

Anatole Louis Garraux nasceu em Paris, a 3 de abril de 1833. Faleceu em 26 de novembro de 1904, em sua residência, nº 60, rue du Faubourg Poissonnière, no décimo arrondissement da capital francesa. Era viúvo e teve três filhas: Marie Louise (Madame Servan), Amélie Henriette Aspasie (Madame Fischer) e Sophie Clarisse (Madame Crétenier).

Seu nome não figura nos copiosos volumes das biografias francesas, sugerindo que não pertencera a nenhuma linhagem aristocrática ou burguesa expressiva. Emigrou para o Brasil aos 17 anos, como atestam seus biógrafos. ${ }^{8}$ Teve relações com a casa Garnier, mas não sabemos de que natureza. Supomos que tenha sido um funcionário da empresa em Paris e, como é próprio da juventude, tenha optado por se aventurar no Rio de Janeiro, em busca de novas oportunidades financeiras. A hipótese é confirmada por Laurence Hallewell, mas o autor infelizmente não a comprova. E como a história não se constrói apenas sobre suposições, afiançamos apenas que, mesmo desconhecendo suas origens e a natureza de sua fortuna, sabemos que nosso personagem logrou fazer bons investimentos e acumular notável riqueza.

Em seu testamento, o autor arrola a doação de diversos souvenirs a parentes próximos e a amigos. São esculturas em bronze, coleção de pinturas, entre as quais telas assinadas por artistas consagrados, enciclopédias, publicações teatrais, relógios, peças em ouro, prataria, móveis finos, amplo apartamento (provido de grande salão, sala de bilhar, escritório), enfim, nosso per- 
sonagem, como ele mesmo o testemunha, foi um homem rico, ostentava hábitos e gostos sofisticados. ${ }^{9}$ Foi um burguês típico do seu tempo.

Estes elementos constituem apenas pequena parte do cabedal herdado pela família.

Os bens declarados após sua morte, em 1904, perfazem a soma de 971.880 F. Ou o equivalente a mil-réis no valor de $748: 348 \$ 062 .{ }^{10}$ Arredondando a cifra para um milhão de francos franceses, em 1905, deduz-se o montante de 20 milhões de francos segundo a tabela de conversão para o ano 2000, constituindo o montante de 3 milhões de Euros atuais ou 4 milhões de dólares! ${ }^{11}$

O livreiro A. L. Garraux se situava na estreita faixa dos $4 \%$ de franceses que deixaram os maiores legados de seu tempo. ${ }^{12}$ Para termos uma idéia da natureza de sua fortuna, observamos que $68 \%$ dos bens declarados se encontravam convertidos em capital financeiro, tendo investido em ações junto a sociedades no México e no Brasil; 27\% em capital industrial; e uma pequena porcentagem (5\%) dividida em bens imobiliários e bens domésticos.

Diante desses dados, podemos concluir que A. L. Garraux seguiu a tendência dos empreendedores da época. Ele aplicou a maior parte de seus bens em investimentos de alto risco, ou seja, no mercado acionário. Fato que constatamos por meio de uma série de lotes de ações desvalorizadas ao lado de outras que mostram índices altos de valorização. E o fez em setores que estavam em franco desenvolvimento nesta nova conjuntura de expansão capitalista: nas empresas de metalurgia; e no sistema de transportes, vias férreas e fluviais, de fundamental importância para a ampliação dos circuitos de comércio em direção a novos centros consumidores. Processo análogo foi observado no Brasil, particularmente no Rio de Janeiro e em São Paulo, marcando uma primeira fase de acumulação e de diversificação do capital investido pelas classes produtoras, período grosso modo balizado entre 1890 e 1914 .

A diversificação de investimentos talvez explique o fato de A. L. Garraux não ter se credenciado como livreiro em Paris. Pelo menos, não foi nesse setor que seu nome passou a figurar nos indicadores profissionais da época. Atuou como comissário de importação e exportação e no comércio de artigos de luxo de origem francesa na capital paulista. Além disso, ele manteve um escritório de comissão e representação em Paris, $n^{\circ}$ 3, rue d'Hauteville. Seus anúncios foram regularmente publicados no Annuaire Firmin-Didot entre 1880 e 1900, quando a empresa anunciou a sucessão para Jablonski, Vogt et Cie. Segundo esse breve anúncio (de uma só linha), publicado sem intervalo nas edições do Annuaire, o empresário fazia remessas de mercadorias pa- 
ra o Brasil e mantinha um escritório para encomendas em São Paulo, certamente, sua livraria. ${ }^{13}$

Não é deveras curioso que, por ocasião da visita da princesa Isabel a São Paulo, a Casa Garraux apareça em seu diário não como exímia livraria, mas como uma casa "cheia de tentações para grandes e pequenos"? ${ }^{14}$ Seria muito provavelmente uma alusão aos livros, em se tratando de uma nobre cultivada, mas também ao vasto mundo de artigos finos expostos em sua loja. Tais como papéis finos, envelopes, vinhos, charutos — os famosos charutos de Havana anunciados nos jornais - entre incontáveis produtos que se confundiam com os artigos da livraria, figurando até mesmo nos catálogos de livros e no seu ex-libris, o que não deixa de ser um traço bastante peculiar.

Dentre os artigos em evidência, destacavam-se: grande sortimento de artigos para desenho; bengalas; binóculos; bolsas (indispensáveis para senhoras); caixas para jóias, para costura; espelhos, quadros; jarras de cristal, de porcelana, jardineiras e uma infinidade de ornamentos: globos celestes, terrestres, mapas geográficos; tinteiros, sinetes, penas de ouro e de madrepérola; vistas fotográficas, opacas e transparentes; instrumentos para serviços de engenharia; vinhos superiores, charutos, fogos de salão e muitos outros objetos.

Malgrado todos esses itens, o que chamava a atenção da clientela era o sortimento de livros da Casa Garraux.

\section{A livraria EM SÃo PAUlO}

É verdade que A. L. Garraux constitui apenas figura pálida no grande mar de histórias a que nos remetem os livros, com seus autores célebres, suas formidáveis histórias editoriais e, mesmo, as quase sempre interessantes histórias de produtores notáveis que inscreveram seu nome no mercado da edição. À sua maneira, ele seguiu os caminhos dos Garnier, particularmente os de Baptiste Louis: instalou-se no Rio de Janeiro, supostamente como empregado da Livraria Garnier, seguiu para a capital paulista como agente de livros franceses, onde logrou tornar-se o maior livreiro da cidade a despeito de outros poucos, mas tradicionais concorrentes, que se beneficiavam do comércio regular com alunos e lentes da Academia de Direito.

Todavia, não podemos afirmar que A. L. Garraux tenha construído, a exemplo de seus conterrâneos, um império do livro. Embora tenha deixado grande fortuna para os descendentes, seus bens estavam muito longe de se equiparar à riqueza acumulada por Hippolyte Garnier, que se tornou o livreiro- 
editor francês mais rico do século XIX. ${ }^{15}$ Ao contrário de Baptiste Louis, fundador da livraria no Rio de Janeiro, A. L. Garraux não deitou raízes no Brasil.

Ele se instalou na cidade de São Paulo no final do ano de 1859. Porém, antes de fundar seu próprio estabelecimento, A. L. Garraux montou um balcão ao lado da livraria do Pândega, onde vendia exemplares do Monde Illustré e da Illustration. Em 1863, abriu a Livraria Acadêmica, no Largo da Sé, no 1, bem próximo à atual rua Quinze de Novembro. Teve como sócios Guelfe de Lailhacar e Raphael Suarèz, como anuncia o catálogo de 1864.

A casa publicou catálogos de livros, que eram distribuídos na capital e no interior da província, e anunciou regularmente seus produtos nos impressos da cidade. Também explorou, o quanto pôde, sua condição de agente cultural francês, posto que não vendia livros apenas, mas, como assinalamos, um leque muito amplo de produtos que concorriam, como se acreditava na época, para a civilização das gentes.

Segundo Raimundo de Menezes, a partir de 1876 a livraria passou por vários proprietários:

para H. Michel, que permaneceu até $1^{\circ}$ de fevereiro de 1883 , quando, por sua vez, a transpassou à firma Fischer, Fernandes \& Cia. Esses passaram-na adiante, em 1ํㅡㄹ de fevereiro de 1888, a Thiollier, Fernandes \& Cia. Era sócio da firma o cidadão francês Alexandre Honoré Marie Thiollier, pai do escritor René Thiollier. Da firma, retirou-se a 28 de fevereiro de 1890 o sócio Fernandes, ficando apenas Mr. Thiollier, que ali permaneceu até 28 de fevereiro de 1896, quando passou a Casa Garraux ${ }^{16}$ à firma Charles Hildebrand \& Cia., que a explorou até 1912. (Menezes, 1971, p.198)

A data de retorno do livreiro Garraux a Paris é incerta.

É improvável que tenha se transferido em definitivo para a capital francesa no ano de 1876. Afinal, no dia 10 de novembro de 1883, o viajante Karl von Koseritz atesta movimento inusitado no hotel em que se hospedara. $\mathrm{O}$ motivo para toda aquela celeuma era a celebração dos casamentos de duas filhas do "livreiro Garraux". ${ }^{17}$

A transmissão da empresa para Henri Michel, "um antigo empregado da livraria”, como declara Raimundo de Menezes, realizou-se no âmbito familiar. Henri Michel foi muito provavelmente marido de Louise Julie, irmã de A. L. Garraux, que assinava pelo sobrenome de Michel. Em 1902, ano da confeç̧ão do testamento, A. L. Garraux declara que sua irmã era divorciada.

Parece-nos igualmente compreensível que a livraria tenha sido transferi- 
da para Willy Fischer, ou William Fernand Gustave Fischer, seu genro, casado com a filha do meio, Henriette Aspasie Julie Garraux, tendo sido este um dos casamentos ao qual alude von Koseritz, no mesmo ano da sucessão da empresa, em 1883. O que nos leva a crer que todas estas primeiras mudanças tivessem se realizado entre familiares, por razões que infelizmente nos escapam à compreensão.

O fato é que na década de 1880, a figura de A. L. Garraux se tornara célebre na sociedade paulistana. Tinha relações com acadêmicos e políticos; havia, enfim, formado sua coterie, como deixa entrever um memorialista:

Essa livraria, disse-me os Dr. Z..., quando nos retirávamos, tem exercido benéfica influência na vida dos paulistas: pode-se mesmo afirmar que em grande parte a ela se deve os elementos da ilustração pública.

- Creio que a podes denominar - importante agência de civilização; está a perder de vista da antiga livraria do Pândega, disse o jornalista, dirigindo-se ao Dr. Z... ${ }^{18}$

Em 1898, o livreiro publicou um catálogo de livros sobre o Brasil, intitulado Bibliographie Brésilienne. A publicação foi alvo de críticas em resenha publicada por Miranda de Azevedo. Texto rigoroso, no qual o autor aponta lapsos de A. L. Garraux quanto à pesquisa bibliográfica realizada. Para tanto, ele se vale de trabalhos já publicados, se bem que não poupa nem mesmo a publicação monumental de Sacramento Blake, e de sua coleção particular. A resenha veio a lume na Revista do Instituto Histórico e Geográfico de São Paulo. ${ }^{19}$ Mas a intenção de Anatole Louis Garraux não parecia outra senão a de prestar homenagem ao Brasil.

\section{A ORGANIZAÇÃO DO COMÉRCIO LIVREIRO}

A Casa Garraux representou para a população paulistana, pelo menos para uma fração potencialmente consumidora, um espaço de inovação. Atributo que não se justifica apenas pela presença destacada de mercadorias européias, que enchiam os olhos daqueles que fitavam as vitrinas da loja, mas também pelo sortimento de títulos que o negociante francês dispôs em seus catálogos.

Nesse aspecto, a firma Garraux, De Lailhacar e Cie. teve atuação exemplar. Organizou uma ampla rede de vendas, tirando proveito das rotas de na- 
vegação e do comércio de cabotagem em vigor na costa brasileira. Lembremos que os navios que percorriam os portos nacionais, de norte a sul, geralmente faziam escalas no Recife, em Salvador e no Rio de Janeiro, não raro estendendo a viagem para Santos — de forma mais regular desde o funcionamento da linha ferroviária que ligava o porto à capital, construída pela empresa de capital britânico São Paulo Railway.

A principal atividade era a importação de livros franceses e sua distribuição nas livrarias do Recife e de São Paulo. Enquanto Garraux se fixou no burgo piratiningano, De Lailhacar, seu sócio, montou uma livraria na rua do Crespo, $\mathrm{n}^{\mathrm{o}}$ 9, tendo sido este reconhecido ponto de encontro da intelectualidade recifense.

Tudo isso possibilitou contatos comerciais regulares não apenas entre o Recife e São Paulo - reforçando os laços espirituais que aproximavam estas duas capitais — mas também com outras cidades portuárias do país.

Todos os catálogos apresentavam o mesmo aviso, em português e em francês: "O Catalogo Geral será enviado gratuitamente sobre pedido, a qualquer ponto do Imperio".

No primeiro Catálogo da livraria, Garraux e De Lailhacar publicam o seguinte texto de apresentação:

O immenso desenvolvimento das letras do Imperio do Brazil devido pela maior parte ao illustre Corpo Acadêmico de S. Paulo, impuz-nós a lei de reformar a nossa livraria de maneira á pol-a ão par do progresso, e das necessidades cada vez maiores do Respeitavel Público.

Para chegar á hum resultado verdadeiramente satisfactorio, não temos poupado sacrificio algum: depois de ter visitado as principais livrarias de França, Bélgica e Portugal, temos celebrado um tractado com os principais editores destes paizes, que nos remettendo directamente e sem intermediario, os seos livros, assim nos permittem de reduzir ainda a modicidade dos nossos preços com hum notavel abatimento.

A presencia permanente em Paris, do nosso socio o Sñr. Raphael Suarez mantendo entre nós relações constantes, estamos habilitados a apresentar aos nossos freguezes as novidades notaveis sobre sciencias e artes, logo depois de sua publicação na Europa. Fiados na benevolencia do Respeitavel Publico os nossos esforços serão attendidos: o único resultado que almejamos sendo de completamente satisfazer as pessoas que se dignão honrar-nos de sua confiança, esperamos que os Nossos Freguezes e em particular o Illustre Corpo Academico se servirão continuar-nos a protecção que até hoje nos tem concedidos.

[Garraux, De Lailhacar \& Cie, S. Paulo, 15 de outubro de 1863]. ${ }^{20}$ 
No início da década de 1870, quando A. L. Garraux aparece consolidado no meio comercial citadino, a sociedade com De Lailhacar foi desfeita. Talvez porque este já se encontrasse, como A. L. Garraux, devidamente instalado no Recife e não mais precisasse da ajuda do sócio. O domínio do mercado local lhe deu meios para estender os negócios com livreiros-editores do Rio de Janeiro, tornando-se distribuidor das obras ali publicadas e até mesmo um concorrente na venda de edições francesas, dada a proximidade das duas capitais. Intenção declarada abertamente no catálogo de 1872:

Aviso - As obras brazileiras editadas no Imperio são vendidas pelo mesmo preço que nas proprias casas dos editores e não são sujeitas a abatimento algum. As obras estrangeiras são vendidas por preços mais baratos que em qualquer outra livraria.

Na mesma Casa há um Catalogo geral das obras portuguezas de educação, litteratura, sciencias, artes, religião, etc., que sera enviado sobre pedido a qualquer ponto do Imperio.

A documentação compulsada não apresenta nenhum aviso sobre as formas de quitação dos livros, no caso de compra a distância, deixando subentendido que esta era feita na forma de depósito nas casas bancárias, o que pressupunha a existência de um sistema financeiro organizado. Ou seja, apenas nos centros urbanos interessava manter os negócios da livraria. Os livreiros também informam que a remessa de livros pelo Correio acarretava uma "augmentação de 15\% sobre os preços de Catalogo".

Fato curioso, os catálogos serviam como regulador de preços no comércio local e em relação a outros centros. É o que observa o bibliotecário da Faculdade de Direito, em 1860:

Sobre as publicações periódicas, escolhi aquelas que me parecem mais uteis á se pode conseguir dos Livreiros como abatimento dos preços que pedem em seus cathalogos, que ordinariamente são sempre os máximos, e elles costumam fazer sempre algum abatimento quando se lhes comprão muitas obras, como no presente cazo. Não posso deixar de submeter a V.Exa., digo, á consideração de V.Exa., que pelos preços que proponho, há Livreiros nesta cidade que se obrigão a vender á Bibliotheca todas as obras pedidas, e a servil-a com as melhores edições e encadernações, e tanto quanto eu creio que se deva preferir a compra aqui nesta 
cidade, não havendo mais em conta na Corte, não obstante, V.Exa. determinará o que julgar melhor.

Deus guarde a V.Exa. por muitos annos. Bibliotheca da Faculdade de Direito de S. Paulo, $1^{\circ}$ de Abril de $1860 .^{21}$

Além disso, os catálogos viabilizaram o conhecimento de toda uma fortuna bibliográfica, difícil de apreender em tempos tão áridos do ponto de vista dos meios de comunicação. Um bibliotecário da Academia de Direito chega a protestar a exigüidade desse material no comércio citadino:

Cidadão Sr. Dr. José Vieira de Carvalho,

Desejando enriquecer tanto quanto possível a Bibliotheca desta Faculdade com a acquisição das primeiras obras que se tem publicado sobre as materias que nella se ensinam, e faltando-me bons dados para esse emprehendimento, por serm muito poucas as livrarias e editoras que nos remetem seus cathalogos, resolvi dirigir-me à Vsa. Excelencia rogando o obsequio de enviar-me até antes de terminar o corrente mez, uma lista das principaes obras escriptas sobre a cadeira que V. Excia. tão sabiamente rege e que sabe não possuir esta Bibliotheca.

Ass. O Bibliothecario Joaquim de Mendonça Junior. ${ }^{22}$

Todas as facilidades que A. L. Garraux encontrou na cidade de São Paulo - uma combinação feliz entre a ausência de um mercado concorrencial e o aumento do público leitor - fizeram que sua livraria passasse a ser reconhecida como superior às do Rio de Janeiro, propaganda que certamente agradava aos paulistas, ciosos em ultrapassar a capital do Império em todas as esferas da vida urbana.

Passemos aos livros anunciados.

\section{Livros E LEITURAS: um BALANÇO DOS CATÁlogos GarRauX}

Segundo Laurence Hallewell, "os catálogos por ela publicados [pela Casa Garraux] oferecem um registro sem igual do que existia disponível para o comprador brasileiro de livros da época" (Hallewell, 1985, p.227).

Os catálogos conformavam pequenos volumes em brochura, organizados por domínios temáticos e separados em dois grandes grupos: edições em português e edições em francês.

A "parte portuguesa", como era chamada, era a menos extensa. No Catá- 
logo de 1866 totalizava 1.187 volumes. O espaço ocupado por essas edições no Catálogo de 1872 é bem mais modesto, embora não possa ser ignorado. Pelas razões apresentadas na parte inicial deste artigo, vamos nos deter a uma descrição da "parte francesa".

Ampla e diversificada, a parte dedicada aos livros franceses totaliza 5.489 títulos no Catálogo de 1866 e aparece assim distribuída: Nouvelles et Romans (1.434; 26,1\%); Littérature (700; 12,8\%); Philosophie (391; 7,1\%); Éditions de Luxe (331; 6,0\%); Variétés (239; 4,4\%); Arts et Métiers (216; 3,9\%); Théatre (215; 3,9\%); Poésie (123; 2,2\%); Voyages (120; 2,2\%); Histoire (110; 2,2\%); Religion (104; 1,9\%); Économie Politique et Sociale (102; 1,9\%); Mathématiques (79; $1,4 \%)$; Grammaire (72; 1,3\%); Agriculture (71; 1,3\%); Musique (61; 1,1\%); Annuaires, Almanachs (54; 1,0\%); Art Militaire (47;0,9\%); Médecine (43;0,8\%); Encyclopédies (20; 0,4\%); Géographie (19;0,3\%); Finances (31;0,6\%).

Algumas seções se cruzam com o programa da Academia de Direito ou do Curso Anexo. São os casos de Filosofia, História, Matemática, Finanças e Economia Política e Social. Neste último item, não podemos perder de vista que desde os seus primórdios a Faculdade foi o principal centro receptor do pensamento político-econômico. De fato, as aquisições mais regulares de livros para a biblioteca, além das obras propriamente jurídicas, foram de teóricos e divulgadores da Economia Política, de Adam Smith — primeiramente em edições francesas - passando por Bentham até Leroy Beaulieu, que teve importante papel como divulgador do liberalismo econômico no final do século. Além desses autores, o exemplar apresenta um conjunto bastante significativo das obras de Proudhon, editadas pela Garnier de Paris.

As obras de Direito são as mais numerosas - depois da seção beletrista - e aparecem organizadas em função do programa do curso jurídico, confirmando o interesse expresso pelos livreiros em atender às necessidades da Academia. Esses títulos ratificam a própria imagem que se fazia do leitor da época, ou seja, era ele um acadêmico, daí seu traço distintivo. Ou, como anuncia uma charge da época: "há aqui uma illustrada Academia; a mocidade ama as sciencias", enquanto "a população sabe dar apreço ás modas e á todos os artefactos de gosto".23

A bibliografia jurídica se distribui nas seguintes áreas: Droit Civil (194; 3,5\%); Droit Romain (162; 3,0\%); Droit Public, Constitutionnel et Politique (123; 2,2\%); ${ }^{24}$ Droit Criminel et Pénal (92; 1,7\%); Droit Commercial (80; 1,5\%); Droit Naturel (79; 1,4\%); Droit Administratif (50; 0,9\%); Droit Ecclésiastique (39; 0,7\%); Droit Maritime (29; 0,5\%); Diplomatie (26; 0,5\%). Os livros de Direito perfazem 907 títulos, ou seja, 16,5\% do total de obras em 
francês catalogadas. Curioso observar que no Catálogo de 1872 o aumento das obras jurídicas não é acentuado, tendo sido anunciados 1.040 títulos.

As edições literárias de origem francesa anunciadas pelos livreiros Garraux e De Lailhacar impõem um problema. Como traduzir em breves linhas semelhante inventário da produção circulante no século XIX? Pois à ampla seção destinada às novelas e romances franceses, agregam-se as seções de Literatura, Teatro e Poesia, igualmente significativas do ponto de vista das tendências e do gosto literário da época, mas também, em termos bibliográficos, da variedade de formatos, ilustrações e outros cuidados bibliográficos que as distinguem.

A seção de literatura organizada no Catálogo de 1866 oferece ao público coleções de "Obras completas dos principais prosadores". Como ocorre no catálogo de obras em português, títulos de ficção se confundem com narrativas históricas, de tal maneira que é possível identificar, nessa mesma seção, os volumes de Ampère, com suas "cenas históricas" da Roma Antiga, ou as obras de Sir Macaulay, traduzidas por Guizot. E, ao lado destas, um painel muito rico da historiografia literária francesa.

O mesmo ecletismo se reflete nos autores mais representativos da parte propriamente literária: Charles André e suas lições de literatura francesa; Bossuet, em "edição infinitamente mais completa do que a publicada por Delestre-Boulange, em 21v., in- $8^{0 \text { "”; }}$ Philarète Chasles, que apresenta significativo conjunto (14 títulos) de obras morais e de crítica literária; de Chateaubriand, a nova edição de suas obras completas, comentadas por Sainte-Beuve, em volumes ilustrados por Delannoy, Thibault, Outhwaite, Mansard, entre outros

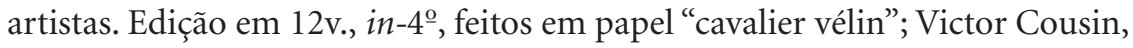
cujas obras somam 60 títulos; Théophile Gautier, 18 títulos; Guizot, 25 títulos; Victor Hugo, em 20 volumes, in- $8^{\circ}$, também vendidos separadamente e outra, com maior descrição de detalhes: “Oeuvres complètes, contendo até sua última obra, Contemplations; edição de luxo, papel cavalier vélin, ornada com 100 gravuras sobre aço e sobre madeira, de Johannot, Raffet, Gavarni, Gérard-Séguin, etc. 20v. in- $4^{\circ}$, reliés".

Além dessa edição, outros 17 títulos, em vários volumes de obras ilustradas, "ricamente ornadas", confirmam a excelência de monsieur Hugo na edição francesa.

Continuando o inventário dos autores eminentes: de Lamartine, 52 títulos, entre os quais uma edição de suas obras completas, em 40 volumes; Michelet, 20 títulos, todos in-8º; Edgard Quinet, 15 títulos; Sainte-Beuve, 14 títulos, em vários volumes cada um, incluindo uma edição em espanhol 
[“Galeria de mujeres celebres, magnifica edición com retratos en acero, 1 tomo en $4^{\circ}$, rica encuadernación com mosaicos, cortes dorados"]; Voltaire, obras completas, em 35 volumes, in $8^{\circ}$. Estes autores se repetem nas outras seções dedicadas às belas-letras, ao lado de autores não citados, mas conhecidos no meio letrado, como Balzac, Eugène Sue, Gustave Flaubert, Alexandre Dumas, Musset, Merimée, enfim, é absolutamente inacreditável o repertório apresentado por A. L. Garraux ao público leitor paulista.

Em contrapartida, as traduções não são numerosas, contrariando o movimento crescente da livraria estrangeira em Paris nessa mesma época, segundo recente estudo de Diana Cooper-Richet. ${ }^{25}$ Possivelmente porque A. L. Garraux tenha concentrado suas relações comerciais com livreiros-editores franceses, seguindo os passos de B. L. Garnier. Há apenas quatro obras em "língua estrangeira", uma em inglês, Addison, Works, 6 v., in-4º. E, em espanhol:

Cervantes, Obras completas, que contienen: El Quijote, las Novelas, la Galatea, el Viaje al Parnaso, Persiles y Sigismunda, con la vida de Cervantes por Navarette. 4 v., in $-4^{\circ}$ avec portrait, gravure et fac-simile de l'écriture de Cervantes;

Mil y una noches (las), cuentos árabes, traducidos del texto árabe genuino por Gustavo Weil, com anotaciones del mismo y una introduccion del baron Silvestre de Sacy, traducidas al castellano por una Sociedad de Litteratos, nueva edición, ilustrada com unas doscientas láminas de los mejores artistas, 2 tomos en $4^{\circ}$ encuadernados en uno, rica encuadernacion com masaicos, cortes dorados

Martinez de la Rosa. Obras completas. 5 v. in- $4^{\circ}$, bela impressão, bonita edição, com a fotografia do autor.

As traduções são um pouco mais numerosas, mas também insignificantes, se comparadas ao conjunto de autores franceses. Do inglês, há apenas a obra de "Byron (lord), Oeuvres complètes, traduites de l'anglais par Benjamin Laroche, quatre séries. 4 v., in- $8^{\circ}$. 1re. Série: Chil-Harold. 1 v. 2ème. Série: Poëmes. 1 v. 3ème. Série: Drames. 1 v. 4ème. Série: Don Juan. 1 v.”.

Os textos traduzidos do alemão revelam a ascendência de pelo menos dois autores sobre a cultura letrada francesa, o que naturalmente se refletia no meio intelectual brasileiro: Goethe (1749-1832) e Heine (1797-1856). Do primeiro, há a tradução de suas obras completas, em 10 volumes, in- $4^{\circ}$, por Jacques Porchat. Outra edição, aparentemente mais popular, traduzida por Staper, revista e precedida de um estudo por Théophile Gautier fils, em 2 volumes, in- $8^{\circ}$, foi anunciada por três mil-réis o volume. A essa edição, soma-se 
outra série impressa in - $^{\circ}$, realizada por diferentes tradutores (Théophile Gautier fils, Mme. Carlowitz, Saint-René Tallandier, entre outros). De Henri Hei-

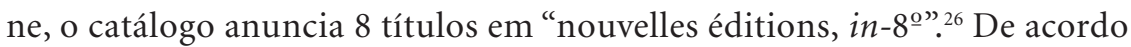
com Diana Cooper-Richet as atividades de livreiros alemães ou de livrarias especializadas em traduções alemãs entraram em franco declínio na década de 1870 , por causa da guerra franco-prussiana.

Desvirtua-se do cânone estabelecido nessas seções de textos literários um conjunto de obras licenciosas, proibidas por lei na França, cujo comércio parece ter recebido o incentivo de B. L. Garnier à época de sua chegada no Rio de Janeiro. O nome da coleção apresentado no Catálogo de 1866 é bastante sugestivo e cede à leitura um tempo para o ócio e o lazer: "Ce que vierge ne doit lire: $1^{\circ}$ Amour d'un page, in $-^{\circ}$ broché; $2^{\circ}$ Contes vrais; $3^{\circ}$ Flagrants délits; $4^{\circ}$ Pommes d'Èves; $5^{\circ}$ Ce que nous font faire les femmes; $6^{\circ}$ L'esprit de reparties; $7^{\circ}$ L'Art d'avoir des maitresses; $8^{\circ}$ Chansons amoureuses".

As leituras de variedades aparecem recompostas em um repertório todo ele modelado por eruditos. São coleções volumosas, de livros de bolso, nas quais os assuntos que tocam o interesse da humanidade, na acepção mais ampla possível do termo, conformam projetos editoriais dirigidos pelas gens de lettres. O Catálogo de 1866 apresenta alguns bons exemplos disso:

- Bibliothèque de Poche, por uma sociedade de sábios e de eruditos. Editado por Paulin e Lechevalier, de 1845 a 1855. Esta biblioteca de bolso contém "variedades curiosas e divertidas das ciências, das letras e das artes, compondo-se de 10v. in- $8^{\circ}$ ".

- Bibliothèque nationale, coleção dos melhores autores, antigos e modernos. Formato in-12, 192 páginas cada volume.

- Bibliothèque Philippart. 100 volumes. "Cada volume com um formato completo".

\section{NOVO CATÁLOGO, NOVAS TENDÊNCIAS}

No Catálogo de 1872 essas coleções ganham espaço mais expressivo, sugerindo seu êxito editorial na França - por se tratar integralmente de edições francesas - e, possivelmente, no Brasil, uma vez que A. L. Garraux teve importante papel como intermediário entre os livros publicados além-mar e o público local. É o que vemos na Tabela 1: 
Tabela 1

Livraria Academica de A. L. Garraux em Lingua Franceza - 1872

\begin{tabular}{lc}
\hline & № de títulos \\
\hline Bibliothèques de Tous Les Ages & 14 \\
Bibliothèques Illustrée & 13 \\
Bibliothèques d'ouvrages propres pour la jeunesse & 44 \\
Bibliothèques de Familles & 28 \\
Bibliothèques variées & 95 \\
\hline & Total: \\
\hline
\end{tabular}

Todas as outras seções, já conhecidas graças à apresentação do catálogo anterior, revelam acentuado aumento do comércio da livraria francesa na capital. Lembramos que no ano de 1872 A. L. Garraux inaugurava a nova sede da Livraria Academica de A. L. Garraux, em belo prédio com fachada de mármore e amplas vitrines, na rua do Rosário (atual Quinze de Novembro).

A mudança do público e, por extensão, das condições do comércio livreiro na capital paulista se traduziram nesse novo Catálogo de obras francesas, cujo perfil se define pelo aumento quantitativo do número de títulos, em relação aos exemplares anteriores e, em termos qualitativos, pela apresentação de outras seções temáticas em consonância com o próprio desenvolvimento da edição francesa. Ou seja, o mercado evoluiu no sentido dos livros de estudos, de conteúdo humanístico ou científico — termo com o qual designamos as obras de ciências exatas - e de narrativas ficcionais - romances, novelas, contos, teatros, poesias: 1.253 títulos de Romances, 685 obras de Literatura, 199 títulos de Poesia e Teatro! Ora, estamos certos de que esse gênero par excellence burguês conquistara seu espaço no meio piratiningano. Enfim, temos nesse Catálogo um curioso guia literário de temas voltados às questões em voga na época, da política às transformações técnicas, ligadas às artes industriais, aos meios de transportes e de comunicações.

A literatura estrangeira expressa em língua original (inglês, alemão, espanhol, italiano, latim) figura pela primeira vez nos Catálogos da Casa Garraux, aproximando a livraria de um novo público, não necessariamente francófono, mas atento ao poliglotismo. Essa mudança de conduta sugere alterações na estrutura demográfica da capital, notadamente quanto à participação de estrangeiros nos setores de serviços e ao novo direcionamento in- 
telectual das elites, que passaram a adotar diferentes referenciais culturais nas últimas décadas do século.

Todos esses aspectos e uma visão de conjunto do exemplar de 1872 podem ser vislumbrados na Tabela 2:

Tabela 2

Livraria Academica de A. L. Garraux em Língua Franceza - 1872

\begin{tabular}{|c|c|c|c|}
\hline \multicolumn{2}{|l|}{ Assuntos } & $\mathrm{N}^{\mathrm{o}}$ de títulos & $\%$ \\
\hline \multicolumn{2}{|l|}{ Romans } & 1.253 & $25,6 \%$ \\
\hline \multicolumn{2}{|l|}{ Littérature } & 685 & $14,0 \%$ \\
\hline \multicolumn{2}{|c|}{ Histoire et Sciences Accessoires } & 313 & $6,4 \%$ \\
\hline \multicolumn{2}{|l|}{ Philosophie } & 271 & $5,5 \%$ \\
\hline \multicolumn{2}{|l|}{ Religion } & 263 & $5,4 \%$ \\
\hline \multicolumn{2}{|l|}{ Science Sociale } & 215 & $4,4 \%$ \\
\hline \multicolumn{2}{|l|}{ Poésie et Théatre } & 199 & $4,1 \%$ \\
\hline \multicolumn{2}{|l|}{ Voyages } & 186 & $3,8 \%$ \\
\hline \multicolumn{2}{|l|}{ Sciences Médicales } & 151 & $3,1 \%$ \\
\hline \multicolumn{2}{|l|}{ Sciences Naturelles } & 114 & $2,3 \%$ \\
\hline \multicolumn{2}{|c|}{ Sciences Mathématiques } & 70 & $1,4 \%$ \\
\hline \multicolumn{2}{|c|}{ Ouvrages Relatifs Aux Événements Politiques De La France } & 55 & $1,1 \%$ \\
\hline \multicolumn{2}{|l|}{ Ouvrages Critiques } & 48 & $1,0 \%$ \\
\hline \multicolumn{2}{|l|}{ Instruction Publique } & 34 & $0,7 \%$ \\
\hline \multicolumn{2}{|l|}{ Géographie } & 24 & $0,5 \%$ \\
\hline \multicolumn{4}{|c|}{ Technologie. Beaux-Arts... } \\
\hline Première partie & $\begin{array}{l}\text { Chemins de fer, Routes, } \\
\text { Machines, Mécanique, } \\
\text { Construction, Télégraphie, } \\
\text { Architecture, Dessin }\end{array}$ & 92 & $1,9 \%$ \\
\hline
\end{tabular}


Industries, Arts-et-Métiers, Agriculture,

Horticulture, Economie domestique,

Deuxième partie Photographie, Musique, Encyclopédie, 263

Jeux, Magnétisme, Spiritisme, Sténographie,

Franc-Maçonnerie, etc.

Philologie, Linguistique, Éducation

Grammaires, Guides de conversation, Alphabets.

Rhétorique, Logique et Morale, Littérature classique.

$19 \quad 0,4 \%$

Dictionnaire em toutes langues

$54 \quad 1,1 \%$

Littérature Etrangère (Langues originales)

Anglais

$300 \quad 6,1 \%$

Allemand

$53 \quad 1,1 \%$

Espagnol

$35 \quad 0,7 \%$

Italien

$32 \quad 0,7 \%$

Latin

$16 \quad 0,3 \%$

Ouvrages Divers

35

$0,7 \%$

Total:

4.890

\section{CONSIDERAÇÕES FINAIS}

Os comentários são parciais e a própria leitura de um catálogo não está isenta de anacronismos.

Geralmente os autores e os títulos destacados são aqueles que se individualizaram na massa anônima de escritores, marcando sua passagem em determinada corrente literária. Muitos outros autores listados nas mesmas condições e ocupando talvez os mesmos espaços no mercado literário da época se tornaram com o tempo ilustres desconhecidos e escapam à atenção do historiador. O que torna a avaliação desse tipo de documento válida somente do ponto de vista da circulação e da busca do perfil da livraria e dos leitores aos quais esses catálogos se dirigem. Abordagens de conteúdo, que não ousamos fazer a menos em algumas raras seções, devem ser aproveitadas em outros es- 
tudos, que dão conta da recepção de textos nacionais e estrangeiros em diferentes áreas do conhecimento.

Nesse sentido, buscamos apresentar, da forma mais breve possível, um panorama da literatura posta em evidência pela Livraria de A. L. Garraux e Guelfe de Lailhacar, nos primeiros anos de atividade em São Paulo e depois, quando o livreiro A. L. Garraux passou a atuar sozinho no mercado local. Os números avultam em todas as seções, e uma rápida passagem pelos títulos nos convence de que esses livreiros formaram uma coleção tanto extensa quanto heterogênea, buscando contemplar as várias correntes de pensamento da época, em diferentes domínios, fazendo que os gostos, as modas e, principalmente, os leitores fossem amplamente agraciados.

Nesse aspecto, o Catálogo de 1872, mais diversificado do ponto de vista das coleções e das matérias que apresenta, oferece subsídios para a identificação da clientela perseguida por A. L. Garraux e o duplo papel do livreiro, que atuou a um só tempo como comerciante e agente cultural.

\section{NOTAS}

${ }^{1}$ Este artigo recupera parte da discussão sobre os circuitos do livro na cidade São Paulo, no século XIX, realizada na tese de doutoramento No Império das letras: circulação e consumo de livros na São Paulo oitocentista, São Paulo, FFLCH-USP, 2006. O projeto de pesquisa foi financiado pela Fapesp.

${ }^{2}$ NABUCO, Joaquim. Minha formação. São Paulo: Progresso Editorial, 1947. p.49.

${ }^{3}$ FRIEIRO, Eduardo, O diabo na livraria do cônego. 2.ed. Belo Horizonte: Itatiaia, 1981. p.51. [1.ed.: 1957].

${ }^{4}$ Edmund Burke, Bentham, Macaulay, aparecem não raro em edições francesas. O próprio Guizot traduzia textos ingleses, dentre eles, os escritos de Sir Lord Thomas Babington Macaulay, com quem estreitou relações de amizade, na época do exílio na Inglaterra. MACAULAY, Sir Lord Thomas Babington. Ensaios históricos. Tradução e estudo crítico de Antonio Ruas. São Paulo: Cia. Ed. Nacional, 1940. t.1, p.27. Das obras traduzidas, o Catálogo Garraux, de 1866, apresenta os seguintes títulos: Essais sur l'histoire de l'Angleterre, 1v., in- $4^{\circ}$; Essais littéraires, $1 \mathrm{v}$. , in $-4^{\circ}$; Histoire et critique, $1 \mathrm{v}$. , in $-4^{\circ}$.

${ }^{5}$ HALLEWELL, Laurence, O livro no Brasil. São Paulo: T. A. Queiroz; Edusp, 1985. [2.ed. rev. e ampliada. São Paulo: Edusp, 2005].

${ }^{6}$ Ver ESTIVALS, Robert. "Création, consommation et production intellectuelles". In: ESCARPIT, Robert. Le littéraire et le social. Paris: Champs; Flammarion, s.d. p.9-42.

${ }^{7}$ Ver MOLLIER, Jean-Yves. L'argent et les lettres. Paris: Fayard, 1999.

${ }^{8}$ Não existe propriamente uma biografia de A. L. Garraux, apenas notas biográficas que 
rememoram sua passagem pela cidade de São Paulo: MENEZES, Raimundo, "As primeiras e mais antigas livrarias de S. Paulo". Revista do Arquivo Municipal, 1971, n.182, p.193-218 [1.ed. 1935]; REZENDE, Carlos Penteado de. "Anatole Louis Garraux". O Estado de S. Paulo. 24 dez. 1959 ; BARBOSA, Francisco de Assis. "Alguns aspectos da influência francesa no Brasil (notas em torno de Anatole Louis Garraux e da sua livraria em São Paulo)". In: GARRAUX, Anatole Louis. Bibliographie Brésilienne. 2.ed. fac-similar. Rio de Janeiro: J. Olympio Ed., 1962; Laurence Hallewell, 1985, cit.

${ }^{9}$ Depôt des testaments et codicilles de M. Garraux. 30 Novembre 1904 - 16 Mai 1908. Maître Jacques Fontana-Notaire. Paris.

${ }^{10}$ Segundo a cotação cambial utilizada em dezembro de 1904, por ocasião do levantamento dos bens declarados: $1 \mathrm{~F}=770$ réis.

${ }^{11}$ Administration de l'enregistrement des domaines et du timbre. Formule de déclaration de mutation par décès - Succession de M. Garraux. Archives de Paris, série D Q7-33378, 1904. Agradeço imensamente ao professor J.-Y. Mollier pela contribuição à leitura desse documento.

${ }^{12}$ Em 1911, essa faixa sofre sensível aumento para 6\% das fortunas reconstituídas a partir das declarações de sucessão, cujos valores estavam compreendidos entre 50 mil francos e 1 milhão de francos. Os dados apresentados valem para Paris. DAUMARD, Adeline, Os burgueses e a burguesia na França. São Paulo: Martins Fontes, 1992. p.109.

${ }^{13}$ Annuaire-Almanach du Commerce, de l'Industrie de la Magistrature et de l'Administration ou Almanach des 1.500 .000 adresses de Paris, des Départements, des Colonies et des pays étrangers. Didot-Bottin, [1850-1905]. Exemplares microfilmados — Bibliothèque Nationale de France.

14 “Diário da Princesa Isabel”. In: Moura, Carlos Marcondes de (Org.). Vida cotidiana em São Paulo no século XIX. São Paulo: Ed. Unesp; Ateliê; Imesp, 1998. p.243.

15 "Diante da impossibilidade de percorrer a declaração de sucessão desse homem de negócios, contentemo-nos com uma avaliação plana: ao menos 15 milhões para o parque imobiliário, 3 para a empresa, temos já 18 milhões, um pouco mais do que o total da fortuna de Calmann Lévy em 1891. Supondo a existência de uma carteira mobiliária, veremos por que motivo esta sugestão não é gratuita; aplicações russas, então na moda, e contas bancárias, mais ou menos guarnecidas, no Rothschild e na Banque de France, onde era cliente, sua fortuna real deve girar em torno de 25 milhões, cifra evidentemente considerável. De qualquer maneira isso nos basta, o editor mais rico da França do século XIX foi Hippolyte Garnier, tendo se tornado um exemplo de sucesso, a um só tempo econômico e social, em um domínio onde possivelmente não teríamos buscado esse perfil de empreendedor". MOLLIER, Jean-Yves, 1999, p.245. Tradução nossa.

${ }^{16}$ Note-se que ela mantém o mesmo nome, tal era a popularidade de seu fundador.

${ }^{17}$ Karl von Koseritz. Imagens do Brasil. São Paulo: Martins, 1943. p.267.

${ }^{18}$ DINIZ, Firmo Albuquerque [Junius]. Em São Paulo — notas de viagem. São Paulo: Governo do Estado, 1978. p.85, grifos meus. 
${ }^{19}$ Revista do Instituto Histórico e Geográfico de São Paulo, n.3, 1898. São Paulo: Typographia “El Diario Español”. p.607-616.

${ }^{20}$ Livraria Garraux, De Lailhacar \& Cie. Catálogo dos livros necessários para os cursos jurídicos da Academia de São Paulo. Largo da Sé, nº 1, 1864. O texto foi muito provavelmente escrito do próprio punho dos autores, fato que se observa pelos erros que apresenta.

${ }^{21}$ Ao que informa, no mesmo ofício: "O contrato feito com o livreiro A. L. Garraux foi o que melhores condições offereceu a esta Bibliotheca abatendo $10 \%$ dos preços pedidos pelos outros livreiros, servindo a bibliotheca com as melhores e mais novas edições, e boas enquadernações das Obras ... Bibliotecário responsável: José Innocencio de Moraes Vieira”. Manuscritos do Arquivo da Faculdade de Direito [doravante, MAFD], Livro 5.

${ }^{22}$ Correspondência de 22 ago. 1882. MAFD, Livro 18.

${ }^{23}$ Cabrião. Semanário humorístico editado por Angelo Agostini, Américo de Campos e Antonio Manoel dos Reis, 1866-1867. Edição fac-similar. 2.ed. rev. e aumentada. Introdução de Delio Freire dos Santos. São Paulo: Unesp; Imprensa Oficial, 2000. p.84. Curioso notar que o Diabo Coxo dedica nos últimos números, em 1865, uma pequena vinheta à Casa Garraux, destacando não exatamente os livros, mas o forte apelo ao consumo que tem essa loja. Ver Diabo Coxo. Edição fac-similar. São Paulo: Edusp, 2005. s.n.p.

${ }^{24}$ Nessa seção há muitas obras de interesse político que aproximavam o leitor nacional da história e do pensamento político francês: Buchez et Roux, Histoire parlamentaire de la

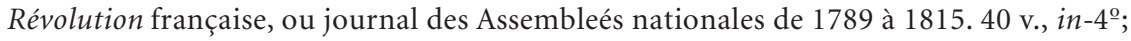
Compte-rendu des séances de l'Assemblée Nationale. Exposé des motifs et projets de lois présentées par le gouvernement de Mai 1848. Décembre 1851. 29 v. in-folio, y compris les tables; Simonde de Sismondi, Études sur les constitutions des peuples libres. $1 \mathrm{v}$. in- $4^{\circ}$ ou $2 \mathrm{v}$. in-4º; Tocqueville, De la démocracie en Amérique. 3v. in-4․ Catálogo, 1866, p.166-174.

${ }^{25}$ Segundo a autora, "há no mundo dos editores parisienses do século XIX um pequeno número de casas - menos de uma dúzia - que se consagraram ao mercado de impressos em língua estrangeira. Esta atividade, iniciada antes da Revolução, por Théophile Barrois, será seguida ao longo do século XIX. Ela é organizada em três domínios temáticos lingüísticos dominantes: inglês, alemão e espanhol". Cf. Diana Cooper-Richet, "Littérature étrangère et monde du livre au XIXème. siècle”, disponível em: www.livroehistoriaeditorial.pro.br.

${ }^{26}$ São os seguintes títulos: De la France; De l'Allemagne, nouvelle édition entièrement revue et augmentée de fragments inédits. $2 \mathrm{v}$. in- $8^{\circ}$; Lutèce, lettres sur la vie politique, artistique et sociale de la France, in- $8^{\circ}$; Poëmes et légendes; Reisebilder, tableaux de voyage; Drames et phantasies; De tout un peu; Oeuvres complètes, 9v.

Artigo recebido em fevereiro de 2008. Aprovado em abril de 2008. 